\title{
Transcriptomic analysis and 3D bioengineering of astrocytes indicate ROCK inhibition produces cytotrophic astrogliosis
}

\section{Ross D. O'Shea ${ }^{1 * t}$, Chew L. Lau ${ }^{2 \dagger}$, Natasha Zulaziz' ${ }^{1}$, Francesca L. Maclean ${ }^{3}$, David R. Nisbet $^{3}$, Malcolm K. Horne ${ }^{2,4}$ and Philip M. Beart ${ }^{2 \dagger}$}

\footnotetext{
1 Department of Physiology, Anatomy and Microbiology, La Trobe University, Bundoora, VIC, Australia

${ }^{2}$ Florey Institute of Neuroscience and Mental Health, University of Melbourne, Parkville, VIC, Australia

${ }^{3}$ Research School of Engineering, The Australian National University, Canberra, ACT, Australia

${ }^{4}$ Department of Neurology, St. Vincent's Hospital, Fitzroy, VIC, Australia
}

Edited by:

Paul Lingor, University Medicine

Göttingen, Germany

\section{Reviewed by:}

Elly M. Hol, Brain Center Rudolf Magnus, Netherlands

Veronica Estrada, Heinrich Heine

University Düsseldorf, Germany

\section{${ }^{*}$ Correspondence:}

Ross D. O'Shea, Department of

Physiology, Anatomy and

Microbiology, La Trobe University,

Health Sciences Building 2,

Bundoora, VIC 3086, Australia

e-mail: r.oshea@latrobe.edu.au

${ }^{t}$ These authors have contributed equally to this work.
Astrocytes provide trophic, structural and metabolic support to neurons, and are considered genuine targets in regenerative neurobiology, as their phenotype arbitrates brain integrity during injury. Inhibitors of Rho kinase (ROCK) cause stellation of cultured 2D astrocytes, increased L-glutamate transport, augmented G-actin, and elevated expression of BDNF and anti-oxidant genes. Here we further explored the signposts of a cytotrophic, "healthy" phenotype by data-mining of our astrocytic transcriptome in the presence of Fasudil. Gene expression profiles of motor and autophagic cellular cascades and inflammatory/angiogenic responses were all inhibited, favoring adoption of an anti-migratory phenotype. Like ROCK inhibition, tissue engineered bioscaffolds can influence the extracellular matrix. We built upon our evidence that astrocytes maintained

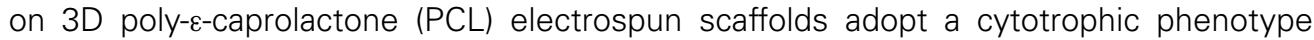
similar to that produced by Fasudil. Using these procedures, employing mature 3D cultured astrocytes, Fasudil $(100 \mu \mathrm{M})$ or $\mathrm{Y} 27632(30 \mu \mathrm{M})$ added for the last $72 \mathrm{~h}$ of culture altered arborization, which featured numerous additional minor processes as shown by GFAP and AHNAK immunolabelling. Both ROCK inhibitors decreased F-actin, but increased G-actin labeling, indicative of disassembly of actin stress fibers. ROCK inhibitors provide additional beneficial effects for bioengineered 3D astrocytes, including enlargement of the overall arbor. Potentially, the combined strategy of bio-compatible scaffolds with ROCK inhibition offers unique advantages for the management of glial scarring. Overall these data emphasize that manipulation of the astrocyte phenotype to achieve a "healthy biology" offers new hope for the management of inflammation in neuropathologies.

Keywords: astrocyte, cytotrophic phenotype, Rho kinase, transcriptome, cell culture, bioengineering

\section{INTRODUCTION}

Astrocytes make important contributions to the maintenance of the function of the mammalian central nervous system (CNS) not only are they the most populous cells, but they play major roles in the maintenance of CNS health through their involvement in energetics, L-glutamate (Glu) homeostasis, anti-oxidant activity and release of trophic factors and gliotransmitters (Ridet et al., 1997; Maragakis and Rothstein, 2006; Parpura et al., 2012).

Abbreviations: CNS, central nervous system; dbcAMP, $\mathrm{N}^{6}, 2^{\prime}-\mathrm{O}-$ dibutyryladenosine $3^{\prime}, 5^{\prime}$-cyclic monophosphate; DRP2, dystrophin related protein 2; EAAT, excitatory amino acid transporter; ECM, extracellular matrix; FOXO, mammalian forkhead members of class O; Glu, L-glutamate; HIF-1, hypoxic-inducible factor 1; KIF, kinesin family member; MFN1, mitofusin 1; MND, motor neurone disease; NFKB1, nuclear factor of kappa light chain gene enhancer in B cells 1; PCL, poly- $\varepsilon$-caprolactone; RAB, member of RAS oncogene family; RHOT1/2, ras homolog gene family members T1/2; ROCK, Rho kinase; SOCS3, suppressor of cytokine signaling 3; SQSTM1, sequestosome 1; STX1A, syntaxin binding protein $1 \mathrm{~A}$; VEGF, vascular endothelial growth factor.
Moreover astrocytes are well documented to be plastic cells that change their morphology, and hence biology, in response to alterations in the extracellular milieu, which may elicit short- and/or long-term responses. These morphological changes occur in normal and pathological brain tissue, and there is an ever expanding literature that astrocytes exist in diverse phenotypes across a continuum exhibiting pro-survival ("cytotrophic") and destructive ("cytotoxic") components (McMillian et al., 1994; Panickar and Norenberg, 2005; Sofroniew and Vinters, 2010). Astrocytes are historically considered to contribute to brain pathologies in a "secondary" mode during what has been termed reactive gliosis (Ridet et al., 1997; Maragakis and Rothstein, 2006), but there is now a solid body of growing evidence supporting their primary role in non-cell autonomous injury, where they secrete toxic entities and/or contribute to proteinopathies, driving disease progression in various neuropathologies (Lobsiger and Cleveland, 2007; Ilieva et al., 2009; Burda and Sofroniew, 2014). Astrocytes 
may contribute to non-cell autonomous injury in motor neurone disease (MND; amyotrophic lateral sclerosis) (Pirooznia et al., 2014) and other neurodegenerative conditions (Di Malta et al., 2012). Whilst the glial scar has long been considered a genuine target for drug development (Mueller et al., 2009), and especially the application of inhibitors of Rho kinase (ROCK) (Mueller et al., 2005), this view is simplistic given advances in our recent knowledge since astrocytes are much more than an inflammatory cell displaying adaptive plasticity in the functioning CNS. Thus many aspects of astrocyte biology offer options as attractive targets to improve their brain health and hence to effect a resultant improvement on synaptic function (Vargas and Johnson, 2010).

Our earlier research demonstrated the association between astrocytic morphology and a number of important aspects of astrocytic function, particularly the abundance and activity of Glu transporters (excitatory amino acid transporters, EAATs). We observed that altering the morphology of astrocytes, using cyclic AMP analogs or ROCK inhibitors, also increased Glu uptake (Lau et al., 2005), elevated transporter $\mathrm{V}_{\max }$ with an approximate doubling of EAAT2 expression at the cell surface and a smaller increase in EAAT1 expression as quantified by biotinylation and immunoblotting (Lau et al., 2011). Similar changes in EAAT activity or abundance were also observed in other treatments altering astrocytic morhpoholgy (Zagami et al., 2005, 2009; O'Shea et al., 2006). We concluded that ROCK inhibitor-induced elevations in Glu transporter function may contribute to their beneficial actions in brain pathologies, since enhanced EAAT activity is likely to be beneficial in CNS injury where excitotoxicity is a common mechanism effecting neurodegeneration (Beart and O'Shea, 2007; Sheldon and Robinson, 2007). Later work led to the hypothesis that changes to the astrocytic cytoskeleton induced by Rho kinase inhibitors were accompanied by the adoption of a "healthy" phenotype. We defined this pro-survival, healthy phenotype as possessing elevated expression of EAAT2, BDNF and key anti-oxidant genes. A shift in the F-/G-actin ratio in favor of G-actin, indicating a reduction in actin stress fibers and alterations to cytoskeletal signaling mechanisms (Kuhn et al., 2000), was also considered integral to this "healthy" phenotype. Much more is known about ROCK inhibitors and their ameliorative actions on destructive ("cytotoxic") glial scarring (Mueller et al., 2005), but our findings reveal diverse "healthy" effects on the astrocyte transcriptome likely to be beneficial in brain injury.

Our continued interest in the relationship between astrocyte morphology and biology led us to apply tissue engineering (Teo et al., 2006) to astrocytes. We found that 3D poly- $\varepsilon$-caprolactone (PCL) scaffolds altered astrocytic responses in vivo in a model of traumatic brain injury (Nisbet et al., 2009). Here our hypothesis was promotion by the bioscaffold of a cytotrophic astrocytic phenotype, so when considered with a likely role for the extracellular matrix (ECM) (Lau et al., 2012), we speculated about links to Rho GTPases, perhaps involving the actin cytoskeleton. In primary culture, astrocytes on 3D PCL scaffolds displayed reduced cytoskeletal stress as confirmed by decreased expression of GFAP and increased G-actin (Lau et al., 2014), and, when maintained over an extended periods, possessed an extensively arborized, stellate morphology. These astrocytes showed a gene expression profile strikingly similar to that of $2 \mathrm{D}$ astrocytes treated with
Fasudil, with up-regulation of genes for EAAT2, BDNF and antioxidant enzymes (Lau et al., 2014). Since 2D astrocytes treated with Rho kinase inhibitors also adopt a stellate shape, our astrocyte transcriptome (Lau et al., 2012) is likely to contain insights into previously unsuspected mechanisms given new literature on this class of molecules.

In this study, we sought to place our findings in their contemporary context (Parpura et al., 2012; Burda and Sofroniew, 2014), by further interrogating our transcriptome after Fasudil treatment through mining this astrocytic database to reveal previously unexplored biological themes. Secondly, given our success with $3 \mathrm{D}$ bioengineered astrocytes, we undertook additional analyses on the possible combined benefits of Rho kinase inhibitors in our 3D culture model. Together these data provide further evidence that ROCK inhibitors produce physiologically beneficial responses in astrocyte biology which are likely to be beneficial in the management of inflammation in diverse neuropathologies.

\section{MATERIALS AND METHODS ANIMALS}

C57BL/6 mice were obtained from the Florey Neuroscience Institutes (Melbourne, VIC, Australia). All experiments receive ethical approval from the Florey Neuroscience Institutes Animal Experimentation Ethics Committee (ethics approval number 07-061). Experiments were performed in accordance with the Prevention of Cruelty to Animals Act 1986 under the guidelines of the National Health and Medical Research Council Code for the Care and Use of Animals for Experimental Purposes in Australia.

\section{BIOENGINEERING, CYTOCHEMISTRY AND NEUROCHEMICAL ASSAYS}

Secondary astrocytic cultures were established from forebrain of postnatal d1.5 mice as described previously (Lau et al., 2011).

Briefly, forebrains were dissected in ice-cold solution (HBSS, Hanks balanced salt salution: $137 \mathrm{mM} \mathrm{NaCl}, 5.37 \mathrm{mM} \mathrm{KCl}$, $4.1 \mathrm{mM} \quad \mathrm{NaHCO}_{3}, 0.44 \mathrm{mM} \quad \mathrm{KH}_{2} \mathrm{PO}_{4}, 0.13 \mathrm{mM} \mathrm{Na} \mathrm{HPO}_{4}$, $10 \mathrm{mM}$ HEPES, $1 \mathrm{mM}$ sodium pyruvate, $13 \mathrm{mM} \mathrm{D}(+)$ glucose, $0.01 \mathrm{~g} / \mathrm{L}$ phenol red), containing $3 \mathrm{mg} / \mathrm{ml}$ bovine serum albumin (BSA) and 1.2 $\mathrm{mM} \mathrm{MgSO}_{4}, \mathrm{pH} 7.4$ ). Cells were dissociated, centrifuged, and the pellet resuspended in astrocytic medium (AM: DMEM, Dulbecco's modified eagle medium, 10\% FBS, $100 \mathrm{U} / \mathrm{ml}$ penicillin/streptomycin, $0.25 \%(\mathrm{v} / \mathrm{v})$ Fungizone $\left.^{\mathrm{TM}}\right)$, preheated to $36.5^{\circ} \mathrm{C}$ at a volume of $5 \mathrm{ml}$ per brain and plated at $10 \mathrm{ml}$ per $75 \mathrm{~cm}^{2}$ flask. Cells were maintained in a humidified incubator supplied with $5 \% \mathrm{CO}_{2}$ at $36.5^{\circ} \mathrm{C}$ and complete medium changes were carried out twice weekly.

After 10 days in vitro (div), when a confluent layer had formed, the cells were shaken overnight $(180 \mathrm{rpm})$ and rinsed in fresh medium to remove non-astrocytic cells. Astrocytes were subsequently detached using $5 \mathrm{mM}$ EDTA $\left(10 \mathrm{~min}\right.$ at $\left.37^{\circ} \mathrm{C}\right)$ and seeded on 96-well plates, random or aligned PCL scaffolds in 96-well plates (all $8 \times 10^{3}$ cells/well) or on $13 \mathrm{~mm}$ glass coverslips (conventional $2 \mathrm{D}$ controls) in 24 -well plates $\left(2 \times 10^{4}\right.$ cells/well). 3D fibrous scaffolds were engineered from unfunctionalized PCL using electrospinning (Nisbet et al., 2009); thicknesses were approximately 250 and $150 \mu \mathrm{m}$ for random and aligned scaffolds, respectively. Astrocytes were treated 8 div later 
with vehicle, $\mathrm{N}^{6}, 2^{\prime}$-O-dibutyryladenosine $3^{\prime}, 5^{\prime}$-cyclic monophosphate (dbcAMP, $1 \mathrm{mM})$, or Rho kinase inhibitors Y27632 $(30 \mu \mathrm{M})$ or Fasudil $(100 \mu \mathrm{M})$ for a further $72 \mathrm{~h}$ when biochemical and morphological analyses were undertaken.

Cytochemistry for GFAP, F-actin and G-actin has been described previously (Lau et al., 2011). For immunocytochemistry, cells were washed with phosphate buffered saline (PBS: $137 \mathrm{mM} \mathrm{NaCl}, 0.5 \mathrm{M} \mathrm{Na}_{2} \mathrm{HPO}_{4}, 0.5 \mathrm{M} \mathrm{NaH}_{2} \mathrm{PO}_{4}$, pH 7.4) and fixed in $4 \%$ paraformaldehyde (PFA) in PBS for $10 \mathrm{~min}$, followed by three washes with Tris buffered saline (TBS: $50 \mathrm{mM}$ Tris- $\mathrm{HCl}, 1.5 \% \mathrm{NaCl}, \mathrm{pH}$ 7.6). Non-specific binding was blocked with $10 \%$ normal goat serum/normal donkey serum (NGS/NDS) in TBS containing $0.3 \%$ Triton X-100. Cells were then incubated with primary antibodies against GFAP (1:1000; Chemicon) or AHNAK (1:500; Molecular Probes), a marker of enlargeosome activity (Racchetti et al., 2012), at $4^{\circ} \mathrm{C}$ overnight on a rocker platform. Cells were then washed and incubated with secondary antibodies (anti-rabbit Alexa Fluor ${ }^{\circledR} 488$ for GFAP 1:500; antimouse Alexa Fluor ${ }^{\circledR 568}$ for AHNAK 1:500; Molecular Probes) and Hoechst 33342 (1:500 dilution) diluted in 2\% (v/v) NGS or NDS in PBS containing $0.3 \%(\mathrm{v} / \mathrm{v})$ Triton X-100 for $3 \mathrm{~h}$ at room temperature. Cells were again washed with PBS three times at room temperature. Coverslips and scaffolds were then mounted on glass microscope slides using Dako fluorescence mounting medium and left to dry in the dark overnight. Both coverslips and scaffolds were stored at $4^{\circ} \mathrm{C}$ until examined by microscopy.

For concurrent labeling of F- and G-actin, cells were washed rapidly with PBS twice by vacuum aspiration and incubated in stabilizing solution $(10 \mathrm{mM}$ Tris base, $0.15 \mathrm{M} \mathrm{NaCl}, 0.01 \%$ Triton $\mathrm{X}-100,2 \mathrm{mM} \mathrm{MgCl} 2,0.2 \mathrm{mM}$ DTT (Bio Vectra, Canada), 10\% glycerol) for $1 \mathrm{~min}$ at $4^{\circ} \mathrm{C}$. Cells were then washed rapidly with chilled PBS $\left(4^{\circ} \mathrm{C}\right)$ twice and fixed in $4 \%(\mathrm{v} / \mathrm{v})$ PFA in PBS for $15 \mathrm{~min}$ at $4^{\circ} \mathrm{C}$. Cells were washed in PBS twice at room temperature and excess PFA was quenched by adding $50 \mathrm{mM} \mathrm{NH}_{4} \mathrm{Cl}$ in PBS for $15 \mathrm{~min}$ at room temperature. Cells were permeabilized in $0.5 \%(\mathrm{v} / \mathrm{v})$ Triton X-100 in PBS for $5 \mathrm{~min}$ and incubated in blocking solution ( $2 \%(\mathrm{v} / \mathrm{v}) \mathrm{BSA}, 0.1 \%(\mathrm{v} / \mathrm{v})$ Triton X-100 in PBS) for $15 \mathrm{~min}$ at room temperature. Following another two washes with PBS, cells were incubated in dye solution (DNaseI-Alexa Fluor 488 1:250; Molecular Probes; rhodamine-phalloidin 1:125 in blocking solution; $\mathrm{BDH}$ ) for $30 \mathrm{~min}$ in the dark. Cells were then washed in PBS three times and mounted on glass microscope slides using Dako fluorescence mounting medium and left to dry in the dark. Cells on scaffolds were mounted by placing the scaffolds with the cells on top, mounted with Dako fluorescence mounting medium and glass coverslips $(13 \mathrm{~mm}$ round; Menzel-Glaser). Slides were stored at $4^{\circ} \mathrm{C}$ until required for imaging.

Methods for measurement of cellular viability [3-(4,5dimethylthiazol-2-yl)-2,5-diphenyltetrazolium bromide (MTT; an index of mitochondrial function) and lactate dehydrogenase assays] have been published (Lau et al., 2011). After treatmentd, MTT was added to the wells give a final concentration of $0.5 \mathrm{mg} / \mathrm{ml}$, incubated with the cells at $36.5^{\circ} \mathrm{C}$ with $5 \% \mathrm{CO} 2$ for $30 \mathrm{~min}$. Media were aspirated and $300 \mu \mathrm{l}$ of dimethyl sulfoxide (DMSO) was added into each well to dissolve the formazan product. The absorbance was subsequently measured at $570 \mathrm{~nm}$ using a Bio-Rad Benchmark Plus microplate spectrophometer. Lactate dehydrogenase (LDH) assay was carried out using a commercially available kit (Roche). Medium $(50 \mu \mathrm{l})$ was collected from each well and placed in a 96-well plate. The samples were incubated with the reaction mixture (Cytotoxicity Detection Kit from Roche) according to the manufacturer's protocol and left in the dark for $30 \mathrm{~min}$. The absorbance of the sample mixture was determined at $490 \mathrm{~nm}$ using a Bio-Rad Benchmark Plus microplate spectrophometer. Data from these experiments were analyzed using Two-Way repeated-measures ANOVA with Bonferroni's post-hoc test using Graphpad Prism software (Version 6).

To examine changes in relative abundance of F-actin and Gactin, the G-actin image was "subtracted" from the corresponding F-actin image after both images were converted to gray-scale, and integrated optical density was measured using ImageJ (NIH: version 1.37). Image analysis used data from 4 images/well from 2 wells/culture over 3 independent cultures. The average value for all fields subjected to the same treatment in an individual experiment was analyzed as a single data point. All images for each form of actin were obtained using the same exposure settings. Statistical comparisons were made using Two-Way repeated-measures ANOVA with Bonferroni's post-hoc test using Graphpad Prism software (Version 6).

\section{MICROARRAY ANALYSES}

Full details have been given previously (Lau et al., 2012), where we validated microarray data by quantitative RT-PCR. Differentially expressed genes between control and Fasudil-treated samples at each time point were then filtered to include only those passing a stringent false cut off of 0.05 . Data have been previously deposited in NCBI's Gene Expression Omnibus and are accessible through GEO Series accession number GSE25829 (Lau et al., 2012).

\section{RESULTS}

\section{NOVEL INSIGHTS FROM TRANSCRIPTOMIC PROFILING INTO BENEFICIAL ACTIONS OF FASUDIL IN ASTROCYTES}

Our initial rationale for undertaking microarray analyses to define the genomic changes induced by Fasudil in astrocytes was the total "disconnect" between the extremely rapid changes in astrocytic shape, which were quite obvious at $30 \mathrm{~min}$, and the alterations in Glu transport which were of a much slower time course ( $\geq 24 \mathrm{~h}$ ) (Lau et al., 2011, 2014). We reasoned that appreciable transcription and new protein synthesis must be taking place to underpin these large changes, and that understanding the molecular changes in astrocytes should allow new mechanistic insights into how ROCK inhibitors provide benefit during brain insults. Our initial bioinformatics revealed that differentially expressed genes at 2 and $6 \mathrm{~h}$ were predominantly down-regulated, and after gene ontology analysis, did not appear to follow any particular biological theme so our focus was on large significant fold changes at later time points ( 12 and $24 \mathrm{~h})$. Our attention thus settled upon major biological processes regulating astrocytic motility and cytoskeletal reorganization viz. actin cytoskeleton, axon guidance, transforming growth factor $-\beta$ signaling and tight junctions. We also found large changes in many genes associated with the ECM (Lau et al., 2012). Here, in view of new understanding that astrocytic responses occur across a continuum that is dependent upon the extent of trauma/disease, and which may resolve when minor and be manageable even in glial scarring by 
pharmacological intervention (Mueller et al., 2009; Sofroniew, 2009), we undertook new mining of our transcriptomic database accessible through GEO Series accession number GSE25829 (Lau et al., 2012).

\section{Transport and molecular motors}

Since our published work had ended with a focus on the pro-survival ("cytotrophic") astrocytic phenotype produced by ROCK inhibition (Lau et al., 2012), we took a step back and focused our attention on mechanistic issues related more broadly to signaling and trafficking events underpinning astrocytic motility and cytoskeletal reorganization. ROCK inhibitors effect disassembly of actin stress fibers and focal adhesions (Mueller et al., 2005), and we documented rapid dissipation (as early as $15 \mathrm{~min}$ ) of phalloidin-labeled actin stress fibers in cultured murine astrocytes treated with Fasudil. Here we demonstrated the actin cytoskeleton underwent a transition to a preponderance of G-actin relative to F-actin, which were increased and decreased 4-fold, respectively (Lau et al., 2010). Rho GTPases, notably Rho and Rac, are key regulators of actin and microtubule cytoskeletons, and actin flow can regulate the positioning of the microtubule cytoskeleton. Active transport, be it anteroor retro-grade, plays a key role in the delivery of gene products and cellular organelles and has been studied in detail in neurones - its disruption leads to "transportopathies" in various neurodegenerative conditions (Liu et al., 2012). Very little is known of these events in astrocytes where we found expression profiles of kinesin family members (KIF2A, KIF13A, KIF 18A, and $K I F 21)$, involved in anterograde transport, were down-regulated (2-3 fold) at 2 and $6 \mathrm{~h}$ after Fasudil (KIF2A, Table 1). Dynein and dynactin members linked to the retrograde motor system also displayed reduced expression at early time points but had returned to control by $24 \mathrm{~h}$. We extended these analyses to include GTPase Rabs, which act as molecular switches to mediate vesicular transport along the cytoskeleton by engaging specific motor proteins (Ng and Tang, 2008) — member of RAS oncogene family 3 (RAB3) may play a role in exocytosis in astrocytes and there was a notable down-regulation of the expression of its isoform $R A B 3 D$ at 12 and $24 \mathrm{~h}$ (Table 1). Interestingly two targets of ROCK phosphorylation, syntaxin binding protein $1 \mathrm{~A}$ (STX1A) involved in vesicle docking/fusion (3-fold decrease, $6 \mathrm{~h}$ ), and dystrophin related protein 2 (DRP2, collapsing response mediator protein 2 ; 2 -fold decreases, 12 and $24 \mathrm{~h}$; Table 1) linked to semaphorin-mediated guidance mechanisms (Arimura et al., 2000), were also downregulated. Given the general trend of data here after ROCK inhibition was decreased gene expression, we wondered whether the consequent stellation with astrocytes adopting an aligned linear and a pro-survival phenotype (Lau et al., 2011, 2012) might also reflect transition to a non-migratory state as has been suggested in normal brain (Cárdenas et al., 2014).

\section{Autophagic and lysososmal systems}

Autophagy, a key system regulating cellular homeostasis including protein and organelle degradation, is known to be affected by

Table 1 | Selected genes with expression changes passing the filter of fold change $>\mathbf{2 . 0}$ and FDR $<0.05$ in at least one time point for Fasudil-treated compared with untreated astrocytes.

\begin{tabular}{|c|c|c|c|c|c|c|c|c|c|}
\hline \multirow[t]{2}{*}{ Probeset ID } & \multirow[t]{2}{*}{ Definition } & \multicolumn{2}{|c|}{$2 \mathrm{~h}$} & \multicolumn{2}{|c|}{$6 \mathrm{~h}$} & \multicolumn{2}{|c|}{$12 \mathrm{~h}$} & \multicolumn{2}{|c|}{$24 h$} \\
\hline & & $P$-value & $\begin{array}{l}\text { Fold- } \\
\text { change }\end{array}$ & $P$-value & $\begin{array}{l}\text { Fold- } \\
\text { change }\end{array}$ & $P$-value & $\begin{array}{l}\text { Fold- } \\
\text { change }\end{array}$ & $P$-value & $\begin{array}{l}\text { Fold- } \\
\text { change }\end{array}$ \\
\hline KIF2A & Kinesin family member $2 \mathrm{~A}$ & $8.89 E-03$ & -1.48 & $1.34 E-07$ & -2.89 & 1.89E-01 & 1.20 & 8.36E-01 & -1.03 \\
\hline RAB3D & $\begin{array}{l}\text { Member RAS oncogene } \\
\text { family }\end{array}$ & 8.14E-02 & 1.23 & $7.50 E-03$ & 1.40 & 1.76E-07 & -2.37 & $1.55 E-05$ & -1.88 \\
\hline DRP2 & Dystrophin related protein 2 & $2.06 E-02$ & 1.53 & $5.92 \mathrm{E}-01$ & 1.10 & $5.41 E-05$ & -2.35 & $4.62 E-03$ & -1.71 \\
\hline FOXO1 & Forkhead box 01 & $1.99 E-09$ & -4.19 & $2.62 E-05$ & -2.16 & $1.96 E-04$ & 1.91 & $4.26 E-02$ & 1.36 \\
\hline SOSTM1 & Sequestosome 1 & $1.43 E-03$ & -1.36 & $8.35 E-09$ & -2.17 & $1.04 E-02$ & 1.27 & 2.03E-04 & 1.46 \\
\hline MFN1 & Mitofusin 1 & 4.32E-01 & 1.17 & 7.11E-06 & -3.20 & 3.32E-01 & -1.22 & 2.61E-01 & 1.26 \\
\hline JAK2 & Janus kinase 2 & $3.59 E-02$ & -1.34 & $1.29 E-05$ & -2.10 & $2.78 \mathrm{E}-01$ & 1.16 & $2.71 \mathrm{E}-01$ & 1.16 \\
\hline NFKB1 & $\begin{array}{l}\text { Nuclear factor of kappa light } \\
\text { polypeptide gene enhancer } \\
\text { in B-cells } 1\end{array}$ & $1.24 E-06$ & -1.85 & $1.33 E-03$ & 1.40 & $2.26 E-03$ & 1.37 & 2.67E-01 & 1.11 \\
\hline SOCS3 & $\begin{array}{l}\text { Suppressor of cytokine } \\
\text { signaling } 3\end{array}$ & $4.67 E-08$ & -5.41 & 5.77E-02 & -1.51 & 3.87E-01 & 1.20 & 4.94E-01 & -1.15 \\
\hline HIF1A & $\begin{array}{l}\text { Hypoxia inducible factor } 1, \\
\text { alpha subunit }\end{array}$ & 6.84E-01 & 1.07746 & 3.97E-02 & -1.486 & 1.39E-01 & 1.32015 & 4.31E-01 & 1.15591 \\
\hline VEGFA & $\begin{array}{l}\text { Vascular endothelial growth } \\
\text { factor } A\end{array}$ & $6.18 E-06$ & -3.49 & 8.83E-02 & -1.45 & $2.28 \mathrm{E}-01$ & 1.30 & 5.78E-01 & 1.13 \\
\hline HK2 & Hexokinase 2 & $4.25 E-07$ & -4.96 & $2.95 E-05$ & -3.25 & $3.48 \mathrm{E}-01$ & -1.24 & $1.92 \mathrm{E}-01$ & -1.35 \\
\hline
\end{tabular}

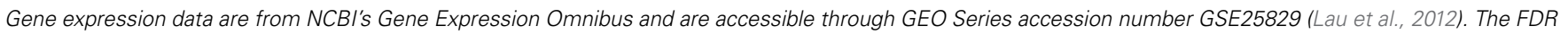

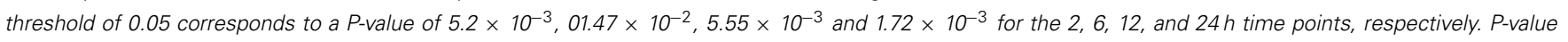
passing the FDR threshold at each time point are italicized. 
ROCK inhibitors, and is also considered a novel target for management of neurodegenerative diseases (Harris and Rubinsztein, 2012). Indeed, actions here would hardly be surprising given the cytoskeletal changes and the fact autophagosomes themselves are membraneous cargo moving along microtubules and transported by the kinesin and dynein/dynactin complex-expression of genes related to molecular motors was generally found to be decreased here. ROCK1/2 regulate actin dynamics and cell migration through phosphorylation of various substrates, but little is known as to how the cytoskeleton influences the activity of the ubiquitin proteasome system and autophagy. ROCK inhibitors have system-dependent actions being reported to accelerate autophagic flux (Mleczak et al., 2013), enhance both UPS and autophagic activity (Bauer et al., 2009), and to inhibit autophagosome formation (Aguilera et al., 2012). The literature on autophagy in astrocytes is relatively small (Dello Russo et al., 2013), but suggestive that as highly plastic glia they adapt to stress and support neurones (Lee et al., 2010; Titler et al., 2013). Mammalian forkhead members of the class O (FOXO) are master signaling integrators influencing many cellular responses, including oxidative stress and inflammation. FOXO pathways are linked to both autophagy and the UPS, and lack of FOXO1 prevents autophagy (Yang et al., 2013). While there is a substantial literature on the role of FOXO1 in inflammation, very little is known about its involvement in astrogliosis. However, recently oxidative-induced injury of astrocytes was reported to involve metallothionein-3 via a FOXO-dependent mechanism (Lee et al., 2014). In our database, substantial reductions were found in the expression of FOXO1 at 2 and $6 \mathrm{~h}$ (4- and 2-fold, respectively) post-Fasudil, although significant changes were not observed at longer times (Table 1). We extended our examination to other autophagic genes and found the expression of sequestosome 1 (SQTM1, p62), a multifunctional scaffolding/adaptor protein interacting with both autophagosomal and proteosomal systems (Korolchuk et al., 2010), was also decreased at both 2 and 6 h (Table 1). Mitochondrial transport is also driven by molecular motors with adaptor proteins linking mitochondria to microtubule-based transport, and there is a rapidly expanding literature on mitochondrial dynamics and recruitment of mitophagy, an unique form of autophagy handing damaged mitochondria (Baker et al., 2014). Expression of mitofusin 1 (MFN1), an outer mitochondrial membrane protein involved in mitochondrial dynamics, was down-regulated 3-fold at $6 \mathrm{~h}$ (Table 1), and had returned to control levels at longer time intervals. Ras homolog gene family members T1/2 (RHOT1/2, Miro1/2), Rho GTPases mediating mitochondrial transport by sensing $\left[\mathrm{Ca}^{2+}\right]$, also underwent two-fold decreases in expression at $6 \mathrm{~h}$. Many genes involved in mitochondrial dynamics, including fission and fusion, contribute to the pathological events in brain pathologies (Wang et al., 2009; Baker et al., 2014). Overall inhibition of Rho kinase results in an astrocyte where protein degradation pathways appear down-regulated initially and then assume a relatively inactive mode consistent with adoption of a healthy, anti-migratory phenotype.

\section{Pro-inflammatory mechanisms}

Inflammatory events related to glial scarring have received attention in the earlier literature (Mueller et al., 2005; Ding et al., 2010; Yu et al., 2010), so we examined these events in our astrocytic system after ROCK inhibition. Unregulated activation of the Janus Kinase-Signal Transducer and Activators of Transcription (JAK-STAT) pathway is a key driver of various inflammatory conditions and has been identified as a target for therapeutic intervention (Kaminska and Swiatek-Machado, 2008). Although less understood in brain, oxidative stress and some cytokines activate via a JAK2-dependent mechanism STAT3 (Planas et al., 2006). Numerous changes, mainly at early timepoints, were noted in these pro-inflammatory mechanisms and were suggestive of decreased activity. Although down-regulation of expression of JAK2 was found at 2 and $6 \mathrm{~h}$ (Table 1), interestingly in our mature cultured astrocytes the expression of STAT3 (data not shown) was unchanged by Fasudil. Although recent elegant work points to a quite precise role of STAT3 in scar-forming astroglia surrounding inflammatory cells in spinal cord injury (Wanner et al., 2013), the recruitment of astrocyte cellular signaling in inflammation appears context dependent (Sofroniew, 2014). We found that the expression of both nuclear factor of kappa light chain gene exchanger in B cells (NFKB1) and suppressor of cytokine signaling (SOCS3) was reduced at $2 \mathrm{~h}$ and had returned to essentially control levels at longer time intervals (Table 1). While NFKB deletion or knockdown reduces inflammation in a number of CNS injury models (Sofroniew, 2014), the regulation of SOCS system is extremely complex generally functioning to reduce chronic inflammation (Linossi et al., 2013). Indeed conditional ablation of SOCS3, but not STAT3, produces contraction of lesion area and notable improvement in functional recovery after spinal cord contusion (Okada et al., 2006).

\section{Hypoxic-inducible factor-1 system and angiogenesis}

We previously characterized the hypoxic-inducible factor-1 (HIF-1) system in an astrocytic model of tolerance against oxidative injury where there was downstream production of vascular endothelial growth factor (VEGF) (Chu et al., 2010). Thus herein we were interested to explore the HIF-1 system and the effects on downstream genes involved in angiogenesis and energetics, since these mechanisms are potentially neuroprotective (Trendelenburg and Dirnagl, 2005). Astrocytes are the major source of brain VEGF in the brain and various stimuli can modulate its induction and secretion (Engelhardt et al., 2014). Whilst inhibition of ROCK can activate VEGF-driven neovascularization and angiogenesis (Kroll et al., 2009), it is very clear the VEGF-mediated responses are concentration- and system-dependent being either beneficial or detrimental in the brain (Ellison et al., 2013). The expression levels of VEGFA and HIF1A were significantly reduced at 2 and $6 \mathrm{~h}$, respectively, and had returned to control levels at longer time intervals (Table 1); significant changes were not found for erythropoietin (data not shown). Whilst a small body of evidence pertinent to astrocytes indicates that HIF1A regulates downstream expression of VEGF (Chavez et al., 2006; Chu et al., 2010), we were surprised to find a large 3-fold decrease of $V E G F A$ at $2 \mathrm{~h}$, evidence which might support the recently described regulation of VEGFA expression independent of HIF1 signaling in astrocytes (Arany et al., 2008; Schmid-Brunclik et al., 2008). Recently, astrocyte-derived VEGFA was reported to drive blood-brain barrier disruption (where astrocytes also retract their endfeet from vessels) in brain inflammatory disease and 
inhibition of VEGFA signaling suggested as a protective approach (Argaw et al., 2012). Astrocytes are less susceptible than neurones to injury by impairment of oxidative metabolism, at least in part because of their capacity to switch to glycolysis, which particularly under conditions of hypoxia is linked to the HIF1 system (Schmid-Brunclik et al., 2008). Here hexokinase 2 (HK2), a key glycolytic enzyme, considered an integral component of the downstream response displayed large reductions in expression at both 2 and $6 \mathrm{~h}$ consistent with the VEGFA data (Table 1).

\section{ROCK INHIBITORS PROVIDE ADDITIONAL BENEFITS FOR ASTROCYTES ON 3D ELECTROSPUN SCAFFOLDS}

\section{Effects of drug treatments on astrocytes cultured on glass} coverslips

Cultures of mouse astrocytes were established on glass coverslips (2D) or on random or aligned PCL scaffolds for 18 div and immunolabeled with antibodies against GFAP and AHNAK. In agreement with previous studies, conventional 2D astrocytes exhibited a more stellate morphology with more extensive processes when treated for 3 days with dbcAMP $(1 \mathrm{mM})$, Fasudil $(100 \mu \mathrm{M})$ or Y27632 $(30 \mu \mathrm{M})$ (Figure 1) (c.f. Lau et al., 2012). Under control conditions, $2 \mathrm{D}$ astrocytes appeared as flattened, polygonal cells and most were GFAP positive. Labeling for AHNAK immunocytochemistry was more widespread and partially co-localized with GFAP under conventional conditions (see below; Figure 1). When treated with dbcAMP, astrocytes appeared to undergo complete stellation, with reduced cell body area and elongated processes. The processes were thicker and shorter when compared to astrocytes treated with both ROCK inhibitors. Interestingly, the staining for AHNAK in astrocytes treated with dbcAMP was relatively darker compared to control (Figure 1). The effects of Y27632 treatment on astrocytes mimicked that of Fasudil. Cells demonstrated increased retraction of cell bodies as well as elongated extensive processes. Labeling patterns for AHNAK, a marker of enlargeosomes (Racchetti et al., 2012), were similar to GFAP distribution, but more widespread under control conditions and following experimental treatments (Figure 1). Notably in all cases GFAP-positive processes were well defined whereas AHNAK labeling of astrocytes was more intense and its distribution through all parts of the astrocytic arbor, including fine processes, made full resolution difficult.

\section{Effects of bioscaffolds on astrocytic morphology}

Astrocytes displayed a different phenotype when cultured on either random or aligned bioscaffolds with cells possessing elongated cell bodies, ramified cell processes and condensed GFAP filaments (Figure 1). On random scaffolds, astrocytes formed tighter clusters, approximately $100-250 \mu \mathrm{m}$ in diameter, but use of aligned bioscaffolds produced astrocytes with more extensive elongated processes (approximately 50$250 \mu \mathrm{m}$ ) following fiber orientation that were distributed in loose clumps. Under control conditions, the labeling pattern for GFAP was found to partially co-localize with AHNAK, although the latter was more widespread, in cultures on both biomatrices, similar to those cultured on glass coverslips (Figure 1).

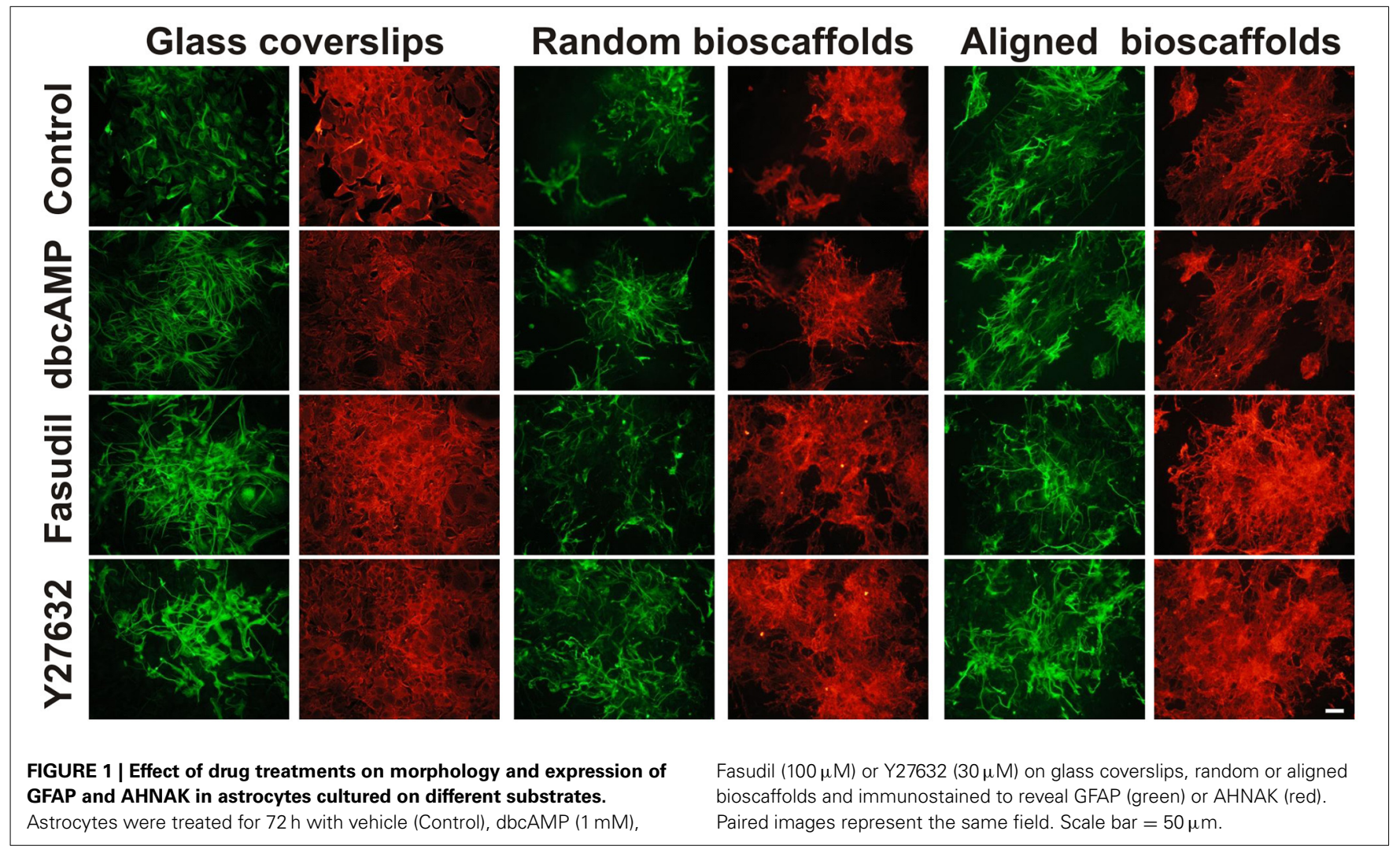




\section{Effects of drug treatments on astrocytes cultured on different substrates}

Astrocytes treated with dbcAMP ( $1 \mathrm{mM}, 72 \mathrm{~h})$ appeared to form clusters on both random (clusters approximately 100-200 $\mu \mathrm{m}$ diameter) and aligned scaffolds (approximately 75-125 $\mu \mathrm{m}$ diameter). In contrast to $2 \mathrm{D}$ cultured astrocytes, the processes were extensive, and outgrowth of the processes was more widespread. Processes infiltrated both type of scaffolds, as previously described (Lau et al., 2014) in random scaffolds (process length approximately $75-150 \mu \mathrm{m}$ ), but there was more growth along aligned fibers (approximately 100-300 $\mu \mathrm{m}$ ) (Figure 1). As was the case in astrocytes cultures on glass coverslips, immunolabeling of AHNAK was more widespread and more ubiquitously expressed through the entire astrocytic arbor than GFAP with which it was generally co-localized in major processes (Figure 1).

When treated with Fasudil $(100 \mu \mathrm{M}, 72 \mathrm{~h})$ astrocytes were evenly distributed and infiltration into both biomatrices was extensive. The processes appeared to be elongated approximately $50-250 \mu \mathrm{m}$ on random scaffolds and $100-300 \mu \mathrm{m}$ on aligned scaffolds, with retracted cell bodies. The process outgrowth was widespread on random bioscaffolds, but astrocytes on aligned bioscaffolds appeared to grow in a similar orientation as those on random scaffolds, and were evenly distributed forming less tight clusters with approximate $200-350 \mu \mathrm{m}$ in diameter on both random and aligned scaffolds (Figure 1). Microscopic examination revealed that the labeling pattern for AHNAK was more widespread through the whole arbor than that of GFAP, which was restricted to major processes, on both biomatrices (Figure 1).
The effects of the other Rho Kinase inhibitor, Y27632, mimicked that of Fasudil. Astrocytes treated with Y27632 $(30 \mu \mathrm{M}$, $72 \mathrm{~h}$ ) also demonstrated extensive processes on both types of scaffolds, however the processes appeared to be longer than in astrocytes treated with Fasudil, with an approximate 150-300 $\mu \mathrm{m}$ in astrocytes cultured on random and approximately $75-350 \mu \mathrm{m}$ length in astrocytes cultured on aligned biomatrices (Figure 1). AHNAK immunolabeling revealed much more of the astrocytic arbor and thus was partially co-localized to GFAP but more widespread.

\section{Effects of drug treatments on actin expression}

Since the actin cytoskeleton plays a determinant role in regulating cellular responses to the extracellular matrix, the effects of fibrillar surfaces on actin dynamics were examined by staining astrocytes for its two forms: F-actin (rhodamine-conjugated phalloidin) and G-actin (Alexa Fluor 488-conjugated DNaseI) (Figure 2). Under control conditions 2D astrocytes displayed well-organized F-actin fibers with densely packed stress fibers and a diffuse expression of globular G-actin. When treated with dbcAMP for $72 \mathrm{~h}$, the intensity of labeling for G-actin increased, while F-actin displayed a prominent change from well-organized actin rings packed with stress fibers to more elongated processes with reduced stress fibers. A similar pattern of changes was found in astrocytes treated with the Rho kinase inhibitors Fasudil and Y27632, where remodeling of the actin cytoskeleton was demonstrated by a shift from F-actin to G-actin predominance. F-actin in astrocytes treated with Y27632 exhibited the same morphology as control, displaying a well-organized ring shape without stress fibers. In contrast,

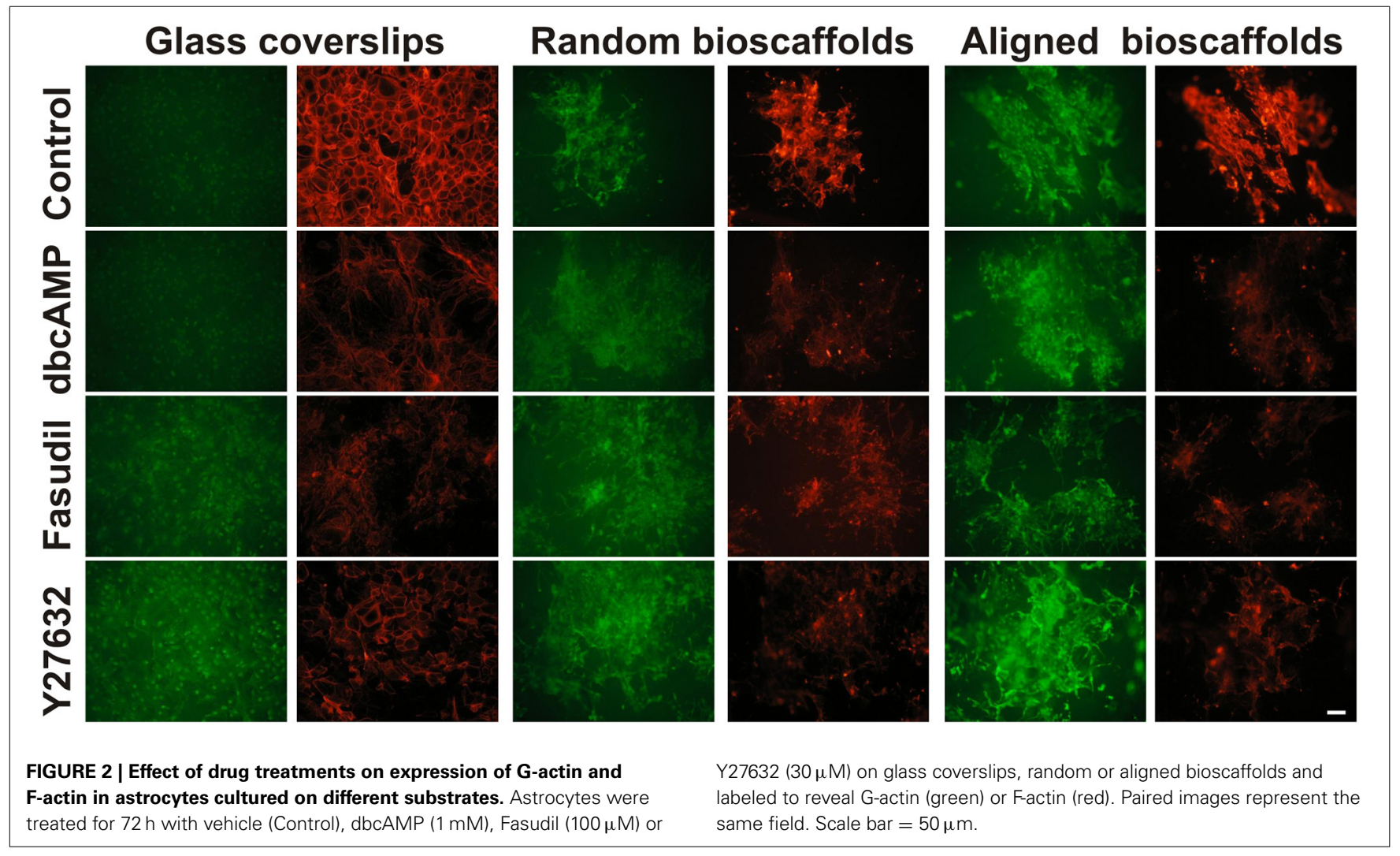


F-actin formed clusters and exhibit a more globular shape in astrocytes treated with Fasudil.

When cultured on random bioscaffolds, F- and G-actin appeared to clump in the absence or presence of drug treatments. Astrocytes treated with dbcAMP and Fasudil displayed wider clumping of both F- and G-actin in relative to control, while cells treated with Y27632 appeared in tighter clusters (Figure 2). On aligned scaffolds, astrocytes formed clumps in the absence or presence of drug treatments. Additionally, under control conditions or following treatment with Y27632, both F-/G-actin clumps appeared to be more "rectangular" in shape, with some increase in longer processes, presumably aligned with the fibers (Figure 2). Astrocytes treated with either dbcAMP or Fasudil formed F-/G-actin in tight small clusters, however F-/G-actin in astrocytes treated with Fasudil displayed elongated processes compared to cells treated with dbcAMP. There was maintenance of overall G-actin labeling under all conditions, and notably with Y27632, whereas all treatments decreased F-actin relative to control (Figure 2).

Image analysis revealed a significant difference in integrated optical density, reflecting a shift from F-actin to G-actin predominance when astrocytes were cultured in $2 \mathrm{D}$ or aligned fibers $(P<0.05$ for all treatments versus Control $)$ after $72 \mathrm{~h}$ treatment (Figure 3). A similar pattern of F-/G-actin ratio shift was observed in astrocytes cultures on random scaffolds but this change was not statistically significant.

\section{Effects of drug treatments on cell viability}

Biochemical analyses of astrocytes cultured on different substrates were undertaken in the absence and presence of drug treatments. Cell viability [3-(4,5-dimethylthiazol-2-yl)-2,5diphenyltetrazolium bromide assay] and cell damage (lactate dehydrogenase assay) revealed no significant detrimental effects of treatments (Figure 4). Minor but significant increases in cell

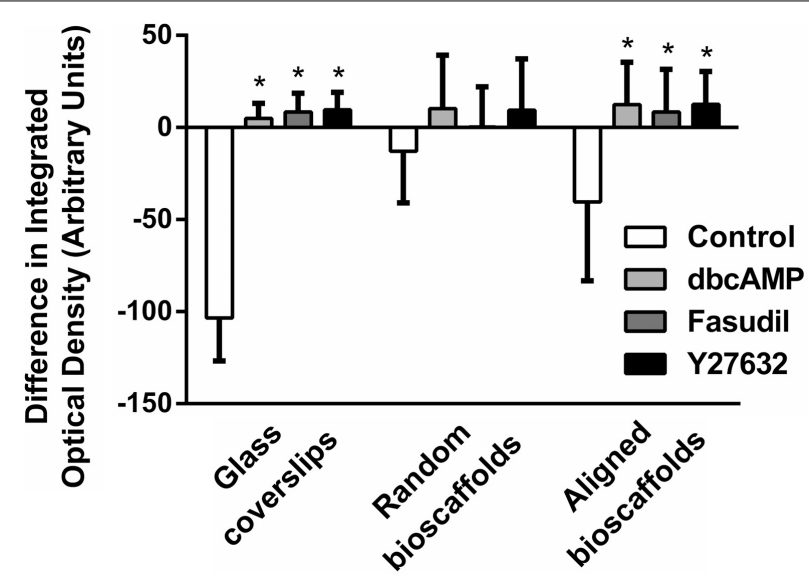

FIGURE 3 | Image analysis of difference in integrated density for F-/Gactin ratio. Astrocytes were treated for $72 \mathrm{~h}$ with vehicle (Control), dbcAMP $(1 \mathrm{mM})$, Fasudil $(100 \mu \mathrm{M})$ or Y27632 (30 $\mu \mathrm{M})$ on glass coverslips, random bioscaffolds or aligned bioscaffolds. ${ }^{*}$ Significantly different from control on same substrate, $p<0.05$. Comparisons were made using Two-Way repeated measures ANOVA with Bonferroni's post-hoc test. Data represent mean \pm S.E.M. $n=6$ (duplicates from 3 individual experiments). viability or decreases in cell damage were observed in some combinations of substrate and drug treatment, but no obvious patterns were apparent. In all cases where significant changes were observed, drug treatments (Fasudil or Y27632) either increased mitochondrial activity or decreased cell damage; detrimental changes were not observed following drug treatments.

\section{DISCUSSION}

Given astrocytes are a plastic glial population existing in various morphologies and displaying diverse biologies, major and wide-ranging effects would be expected upon manipulation of the ROCK/Rho system, a key determinant via actin of cellular survival, migration and proliferation (Riento and Ridley, 2003). Whilst our initial bioinformatic analyses of transcriptomic changes induced by Fasudil were directed at major biological processes regulating cytoskeletal reorganization, we also found significant changes in expression of a diverse group of genes associated with astrocyte function, and suggested that overall ROCK inhibitors would produce "healthy and physiologically beneficial responses in astrocyte biology" (Lau et al., 2012). We thus postulated the existence of a pro-survival, cytotrophic phenotype wherein the essential criteria were a preponderance of G-actin and elevated expression of EAAT2, BDNF and key antioxidant genes. Reappraisal of our bioinformatic data revealed diverse additional effects on the astrocyte transcriptome likely to be beneficial in brain injury. Gene expression profiles of motor and autophagic cellular cascades and inflammatory/angiogenic responses were all inhibited favoring adoption of what might be considered "healthy," anti-migratory phenotype. These types of changes generally have not been a focus in astrocytes, although often documented in neurones, but there is the beginnings of an new literature describing roles for Rho GTPases or actions of ROCK inhibitors in the biological processes reported here (vide supra). This concept of an anti-migratory phenotype (Cárdenas et al., 2014) is an interesting one for in vitro ROCK inhibitors produced very rapid stellation of astrocytes (approximately $15 \mathrm{~min}$ with most changes complete by 3-6 hr), a morphology which in uninjured brain is considered to reflect non-migratory properties, and here may indicate Fasudil produces a normal cytotrophic astrocyte. This state may resemble cytotrophic components of minimal, self-resolving hypertrophy often stated to occur in minor trauma/injury wherein there is re-establishment of a healthy physiological phenotype (Balasingam and Yong, 1996; Sofroniew, 2009; Burda and Sofroniew, 2014). Earlier work has documented the ability of ROCK inhibitors to produce extension of GFAP-positive, presumed astrocytic processes in vitro and in vivo models of nerve crush (Sagawa et al., 2007; Ichikawa et al., 2008). Extensive process formation has also been noted with ROCK inhibitors in wound healing models using astrocytes (Holtje et al., 2005). Such morphological rearrangements as discussed here are underpinned by extensive remodeling of the actin cytoskeleton, particularly lamellipodia and filopodia (Le Clainche and Carlier, 2008; Mattila and Lappalainen, 2008).

Tissue engineering in combination with materials science has been also been employed to manipulate astrocyte biology. We have previously reported in an in vivo model of traumatic brain injury (Nisbet et al., 2009) that, in the presence of PCL 


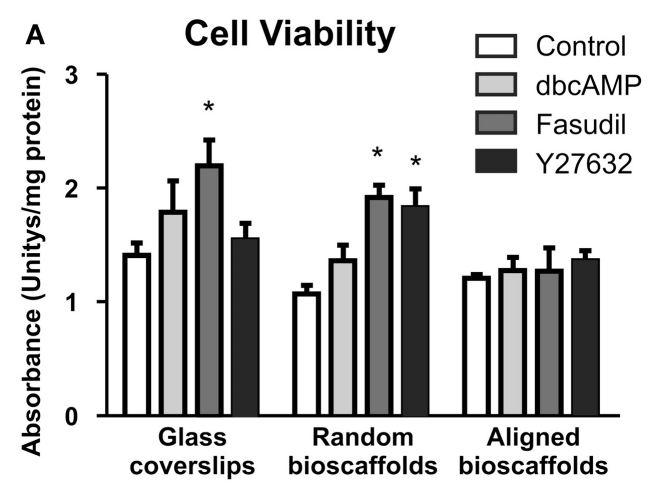

FIGURE 4 | Effect of drug treatments on cell viability and cell damage. Astrocytes were treated for $72 \mathrm{~h}$ with vehicle (Control), dbcAMP (1 mM), Fasudil $(100 \mu \mathrm{M})$ or $\mathrm{Y} 27632(30 \mu \mathrm{M})$ on glass coverslips, random or aligned bioscaffolds. Cell viability was determined by the 3-(4,5-dimethylthia zol-2-yl)-2,5-diphenyltetrazolium bromide assay (A), while cell damage was

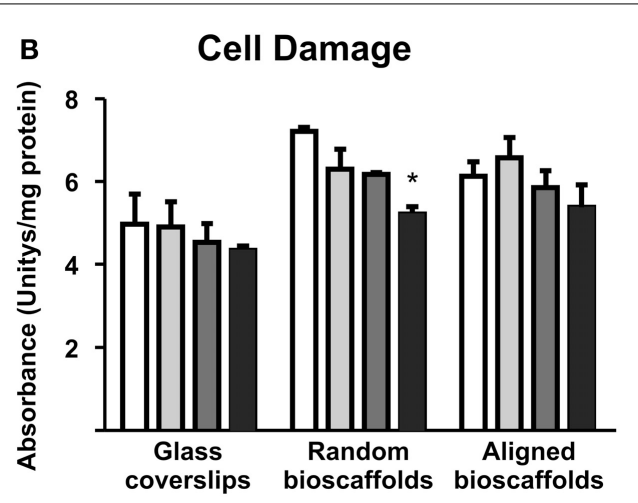

assessed using the lactate dehydrogenase assay (B). *Significantly different from control on same substrate, $p<0.05$. Comparisons were made using Two-Way repeated-measures ANOVA with Bonferroni's post-hoc test. Data represent mean \pm S.E.M. from 3 independent experiments with the average value from each experiment being $n=1$. scaffolds, astrocytes provided signals encouraging neuritic infiltration of injured tissue, with findings favoring the existence of early cytotoxic and late cytotrophic components of astrogliosis. Others have reported variable data with astrocytes in tissue engineering and the literature suggests that the type of engineering approach employed greatly influences the nature of the outcome, and specifically the temporal contributions of cytotrophic vs. cytotoxic astrogliosis (Iannotti et al., 2003; Wong et al., 2007; Nisbet et al., 2010). Nevertheless our success in vivo encouraged us to pursue mechanistic studies with tissue engineering of astrocytes on PCL bioscaffolds where we found in 3D extensive process formation, stellation and adoption of a cytotropic phenotype resembling that found in $2 \mathrm{D}$ astrocytes treated with ROCK inhibitors (vide supra). There have been remarkably few successes where bioengineering strategies in vitro have led to the establishment of viable astrocytes on bioscaffolds (Puschmann et al., 2013; Zuidema et al., 2014), but our use of secondary astrocytes allowed the long term maintenance of mature cells on PCL bioscaffolds (Lau et al., 2014). Given there was a body of evidence for beneficial effects of ROCK inhibitors in models of head and spinal trauma (Raad et al., 2012; Watzlawick et al., 2014) we extended our study to explore whether the inclusion of Fasudil and Y27632 would provide further benefits in our 3D astrocyte model. Here we found that both ROCK inhibitors produced additional GFAP-positive processes relative to PCL scaffolds alone, and there seemed a bonus of a further shift to an even greater preponderance of G-actin relative to Factin. AHNAK, a marker of enlargeosome activity and migration (Racchetti et al., 2012), proved very suitable for immunostaining of fine astrocytic processes, being partially co-localized with GFAP, but revealing much more of the astrocyte arbor than GFAP, an effect which was particularly obvious on aligned bioscaffolds. Overall these data are consistent with ROCK inhibitors providing further beneficial effects over and above PCL scaffolds alone. Preliminary evidence from Western immunoblotting suggested ROCK inhibitors reduced GFAP expression relative to dbcAMP (Supplementary Figure 1), whilst patterns of AHNAK expression were generally consistent with immunocytochemistry. In ongoing work examining Glu transporter activity, we confirmed our previously reported elevation of uptake in 2D astrocytes by Fasudil and Y27632 (Lau et al., 2011), and found EAAT activity appeared to be elevated 2-4 fold in astrocytes maintained on bioscaffolds (data not shown). Whilst we need to undertake further experiments to document fully the phenotype of the astrocytes found here, it does seem that the phenotype may be shifted even further toward the direction of cytotrophic astrogliosis. Our findings here, demonstrating that Fasudil and Y27632 under certain conditions either increased cell viability or decreased cell damage compared with control conditions (Figure 4), provide further evidence for the potential benefits of ROCK inhibitors via direct effects on astrocytes, which may contribute to the beneficial outcomes of these treatments in brain injury. Taken together there would seem to be a case for combining Rho kinase inhibition with tissue engineering in models of traumatic brain and spinal cord injury.

ROCK inhibitors, and especially Fasudil, have been examined in various injury models where astrocytes may contribute to the pathology, perhaps via cytotoxic inflammation, and/or by compromising recovery from trauma/neurodegeneration. Glia, including astrocytes, are known to contribute to the neuropathology of MND through non-cell autonomous mechanisms (Vargas and Johnson, 2010; Pirooznia et al., 2014). MND is a rapidly advancing degenerative condition where suitable new therapeutic strategies are badly needed (Turner and Talbot, 2008), so the pro-survival response produced by Fasudil in the SOD1 mouse model of MND is an impressive advance (Takata et al., 2013; Tonges et al., 2014) since the rapid progression of disease in this model generally does not respond to interventions (Turner and Talbot, 2008). Attentuation of astroglial pathology was noted early after Fasudil treatment whereas beneficial effects were noted at most stages on microglial mediated inflammation (Tonges et al., 2014). Rho kinase inhibitors may also be useful in other neurodegenerative conditions where astrocytes contribute to inflammation, perhaps by non-cell autonomous mechanisms. 
For example in Alzheimer's disease, where astrocytic mechanisms are linked to disease risk factors and where their contribution to synaptic signaling is compromised by amyloid- $\beta$ peptide (Talantova et al., 2013), Fasudil may have therapeutic potential as it suppressed the inflammation in rodent hippocampus induced by amyloid- $\beta$ peptide (Song et al., 2013). In experimental autoimmune encephalomyelitis, an animal model of multiple sclerosis, Fasudil reduced inflammation and demyelination. Early or late administration of Fasudil exerted beneficial effects producing a shift in macrophage function from the cytotoxic M1 to the anti-inflammatory or reparative M2 phenotype in spinal cord and spleen (Liu et al., 2013). Subsequently the same laboratory suggested that at least part of this action of Fasudil was via a diminution of cytotoxic astrogliosis and less infiltration of inflammatory cells across the blood brain barrier (Guo et al., 2014). Interestingly, astrocyte phenotype is now recognized to determine the outcome of CNS repair and myelination, and components of astrocyte biology likely represent valid targets to enhance lesion repair in multiple sclerosis (Barnett and Linington, 2013).

Given the seminal role astrocytes play in synaptic transmission and maintenance of brain function generally, their diverse biology offers many options for potentially "druggable" targetsbeneficial shifts to cytotrophic phenotypes would improve their overall health and ameliorate cytotoxic inflammation in brain pathologies, and thus conceivably allow maintenance of appropriate synaptic function (Vargas and Johnson, 2010). Another often not discussed aspect of astrocyte biology is their multiple "morphological" interfaces, not only via the communication of astrocytic tight junctions, but also with different cellular populations viz. neurones, oligodendrocytes, blood vessels, blood brain barrier and microglia (Volterra and Meldolesi, 2005), including via the quad-partite synapse (Schafer et al., 2013). Thus astrocytes are seminally placed from an organizational perspective to orchestrate the biology of these different CNS populations by integrating synaptic and non-synaptic signaling. The recent work with ROCK inhibitors showing cytotrophic changes in astrocyte function in disease models of MND (Tonges et al., 2014) and multiple sclerosis (Guo et al., 2014) are particularly encouraging. Indeed, we speculate that Fasudil-induced changes in astrocytic phentotype exert beneficial effects which should be taken in a similar context to the much popularized "healthy" shift in macrophage function (now extended to microglia) from the cytotoxic M1 to the reparative M2 phenotype - and which is produced by Fasudil in spinal cord in experimental autoimmune encephalomyelitis (Liu et al., 2013). Meta-analysis of data from experimental studies of spinal cord injury evaluating Rho A/ROCK blockade found significant overall improvement of locomotor function. Overall a possible role in inflammatory events was noted and the strategy was considered a plausible one for management of human spinal cord injury (Watzlawick et al., 2014). Certainly it is clear with advances in the design of increasingly effective ROCK inhibitors (Guan et al., 2013), and with new developments in tissue engineering and drug delivery via nanoparticles that ROCK inhibitors alone or in concert with these new technologies are likely to be widely applicable to management of inflammation in neurodegenerative conditions.

\section{ACKNOWLEDGMENTS}

This research was supported by funding from an NHMRC Project Grant (APP1020332). DN was supported by an Australian Research Council Australian Postdoctoral Fellowship and subsequently by an NHMRC Career Development Fellowship (APP1050684). MH and PB were supported NHMRC Research Fellowships, APP1020401 and APP1019833, respectively. Access to the facilities of the Centre for Advanced Microscopy (CAM) with funding through the Australian Microscopy and Microanalysis Research Facility (AMMRF) is gratefully acknowledged. The Florey Institute of Neuroscience and Mental Health receives infrastructure support from the Victorian State Government (Australia).

\section{SUPPLEMENTARY MATERIAL}

The Supplementary Material for this article can be found online at: http://www.frontiersin.org/journal/10.3389/fnins.2015. 00050/abstract

\section{REFERENCES}

Aguilera, M. O., Beron, W., and Colombo, M. I. (2012). The actin cytoskeleton participates in the early events of autophagosome formation upon starvation induced autophagy. Autophagy 8, 1590-1603. doi: 10.4161/auto.21459

Arany, Z., Foo, S. Y., Ma, Y., Ruas, J. L., Bommi-Reddy, A., Girnun, G., et al. (2008). HIF-independent regulation of VEGF and angiogenesis by the transcriptional coactivator PGC-1alpha. Nature 451, 1008-1012. doi: 10.1038/nature06613

Argaw, A. T., Asp, L., Zhang, J., Navrazhina, K., Pham, T., Mariani, J. N., et al. (2012). Astrocyte-derived VEGF-A drives blood-brain barrier disruption in CNS inflammatory disease. J. Clin. Invest. 122, 2454-2468. doi: 10.1172/JCI60842

Arimura, N., Inagaki, N., Chihara, K., Menager, C., Nakamura, N., Amano, M., et al. (2000). Phosphorylation of collapsin response mediator protein-2 by Rhokinase. Evidence for two separate signaling pathways for growth cone collapse. J. Biol. Chem. 275, 23973-23980. doi: 10.1074/jbc.M001032200

Baker, M. J., Palmer, C. S., and Stojanovski, D. (2014). Mitochondrial protein quality control in health and disease. Br. J. Pharmacol. 171, 1870-1889. doi: 10.1111/bph. 12430

Balasingam, V., and Yong, V. W. (1996). Attenuation of astroglial reactivity by interleukin-10. J. Neurosci. 16, 2945-2955.

Barnett, S. C., and Linington, C. (2013). Myelination: do astrocytes play a role? Neuroscientist 19, 442-450. doi: 10.1177/1073858412465655

Bauer, P. O., Wong, H. K., Oyama, F., Goswami, A., Okuno, M., Kino, Y., et al. (2009). Inhibition of Rho kinases enhances the degradation of mutant huntingtin. J. Biol. Chem. 284, 13153-13164. doi: 10.1074/jbc.M809229200

Beart, P. M., and O'Shea, R. D. (2007). Transporters for L-glutamate: an update on their molecular pharmacology and pathological involvement. Br. J. Pharmacol. 150, 5-17. doi: 10.1038/sj.bjp.0706949

Burda, J. E., and Sofroniew, M. V. (2014). Reactive gliosis and the multicellular response to CNS damage and disease. Neuron 81, 229-248. doi: 10.1016/j.neuron.2013.12.034

Cárdenas, A., Kong, M., Alvarez, A., Maldonado, H., and Leyton, L. (2014). Signaling pathways involved in neuron-astrocyte adhesion and migration. Curr. Mol. Med. 14, 275-290. doi: 10.2174/1566524014666140128113311

Chavez, J. C., Baranova, O., Lin, J., and Pichiule, P. (2006). The transcriptional activator hypoxia inducible factor 2 (HIF-2/EPAS-1) regulates the oxygendependent expression of erythropoietin in cortical astrocytes. J. Neurosci. 26, 9471-9481. doi: 10.1523/JNEUROSCI.2838-06.2006

Chu, P. W., Beart, P. M., and Jones, N. M. (2010). Preconditioning protects against oxidative injury involving hypoxia-inducible factor-1 and vascular endothelial growth factor in cultured astrocytes. Eur. J. Pharmacol. 633, 24-32. doi: 10.1016/j.ejphar.2010.02.008

Dello Russo, C., Lisi, L., Feinstein, D. L., and Navarra, P. (2013). mTOR kinase, a key player in the regulation of glial functions: relevance for the therapy of multiple sclerosis. Glia 61, 301-311. doi: 10.1002/glia.22433 
Di Malta, C., Fryer, J. D., Settembre, C., and Ballabio, A. (2012). Astrocyte dysfunction triggers neurodegeneration in a lysosomal storage disorder. Proc. Natl. Acad. Sci. U.S.A. 109, E2334-E2342. doi: 10.1073/pnas.1209577109

Ding, J., Li, Q. Y., Yu, J. Z., Wang, X., Sun, C. H., Lu, C. Z., et al. (2010). Fasudil, a Rho kinase inhibitor, drives mobilization of adult neural stem cells after hypoxia/reoxygenation injury in mice. Mol. Cell. Neurosci. 43, 201-208. doi: 10.1016/j.mcn.2009.11.001

Ellison, S. M., Trabalza, A., Tisato, V., Pazarentzos, E., Lee, S., Papadaki, V., et al. (2013). Dose-dependent neuroprotection of $\operatorname{VEGF(1)(6)(5)~in~Huntington's~}$ disease striatum. Mol. Ther. 21, 1862-1875. doi: 10.1038/mt.2013.132

Engelhardt, S., Patkar, S., and Ogunshola, O. O. (2014). Cell-specific blood-brain barrier regulation in health and disease: a focus on hypoxia. Br. J. Pharmacol. 171, 1210-1230. doi: 10.1111/bph.12489

Guan, R., Xu, X., Chen, M., Hu, H., Ge, H., Wen, S., et al. (2013). Advances in the studies of roles of Rho/Rho-kinase in diseases and the development of its inhibitors. Eur. J. Med. Chem. 70, 613-622. doi: 10.1016/j.ejmech.2013. 10.048

Guo, M. F., Meng, J., Li, Y. H., Yu, J. Z., Liu, C. Y., Feng, L., et al. (2014). The inhibition of Rho kinase blocks cell migration and accumulation possibly by challenging inflammatory cytokines and chemokines on astrocytes. J. Neurol. Sci. 343, 69-75. doi: 10.1016/j.jns.2014.05.034

Harris, H., and Rubinsztein, D. C. (2012). Control of autophagy as a therapy for neurodegenerative disease. Nat. Rev. Neurol. 8, 108-117. doi: 10.1038/nrneurol.2011.200

Holtje, M., Hoffmann, A., Hofmann, F., Mucke, C., Grosse, G., Van Rooijen, N., et al. (2005). Role of Rho GTPase in astrocyte morphology and migratory response during in vitro wound healing. J. Neurochem. 95, 1237-1248. doi: 10.1111/j.1471-4159.2005.03443.x

Iannotti, C., Li, H., Yan, P., Lu, X., Wirthlin, L., and Xu, X. M. (2003). Glial cell line-derived neurotrophic factor-enriched bridging transplants promote propriospinal axonal regeneration and enhance myelination after spinal cord injury. Exp. Neurol. 183, 379-393. doi: 10.1016/S0014-4886(03)00188-2

Ichikawa, M., Yoshida, J., Saito, K., Sagawa, H., Tokita, Y., and Watanabe, M. (2008). Differential effects of two ROCK inhibitors, Fasudil and Y27632, on optic nerve regeneration in adult cats. Brain Res. 1201, 23-33. doi: 10.1016/j.brainres.2008.01.063

Ilieva, H., Polymenidou, M., and Cleveland, D. W. (2009). Non-cell autonomous toxicity in neurodegenerative disorders: ALS and beyond. J. Cell. Biol. 187, 761-772 doi: 10.1083/jcb.200908164

Kaminska, B., and Swiatek-Machado, K. (2008). Targeting signaling pathways with small molecules to treat autoimmune disorders. Expert Rev. Clin. Immunol. 4, 93-112. doi: 10.1586/1744666X.4.1.93

Korolchuk, V. I., Menzies, F. M., and Rubinsztein, D. C. (2010). Mechanisms of cross-talk between the ubiquitin-proteasome and autophagy-lysosome systems. FEBS Lett. 584, 1393-1398. doi: 10.1016/j.febslet.2009.12.047

Kroll, J., Epting, D., Kern, K., Dietz, C. T., Feng, Y., Hammes, H. P., et al. (2009). Inhibition of Rho-dependent kinases ROCK I/II activates VEGF-driven retinal neovascularization and sprouting angiogenesis. Am. J Physiol. Heart. Circ. Physiol. 296, H893-H899. doi: 10.1152/ajpheart.01038.2008

Kuhn, T. B., Meberg, P. J., Brown, M. D., Bernstein, B. W., Minamide, L. S., Jensen, J. R., et al. (2000). Regulating actin dynamics in neuronal growth cones by ADF/cofilin and rho family GTPases. J. Neurobiol. 44, 126-144. doi: 10.1002/1097-4695(200008)44:2<126::AID-NEU4>3.0.CO;2-Z

Lau, C. L., Beart, P. M., and O'Shea, R., D. (2005). Upregulation of glutamate transporter activity with changes in astrocytic phenotype. J. Neurochem. 94, 1. doi: 10.1111/j.1476-5381.2011.01259.x

Lau, C. L., Beart, P. M., and O'Shea, R. D. (2010). Transportable and nontransportable inhibitors of L-glutamate uptake produce astrocytic stellation and increase EAAT2 cell surface expression. Neurochem. Res. 35, 735-742. doi: 10.1007/s11064-010-0130-6

Lau, C. L., Kovacevic, M., Tingleff, T. S., Forsythe, J. S., Cate, H. S., Merlo, D., et al. (2014). 3D Electrospun scaffolds promote a cytotrophic phenotype of cultured primary astrocytes. J. Neurochem. 130, 215-226. doi: 10.1111/jnc.12702

Lau, C. L., O'Shea, R. D., Broberg, B. V., Bischof, L., and Beart, P. M. (2011). The Rho kinase inhibitor Fasudil up-regulates astrocytic glutamate transport subsequent to actin remodelling in murine cultured astrocytes. Br. J. Pharmacol. 163, 533-545. doi: 10.1111/j.1476-5381.2011.01259.x

Lau, C. L., Perreau, V. M., Chen, M. J., Cate, H. S., Merlo, D., Cheung, N. S., et al. (2012). Transcriptomic profiling of astrocytes treated with the Rho kinase inhibitor fasudil reveals cytoskeletal and pro-survival responses. J. Cell. Physiol. 227, 1199-1211. doi: 10.1002/jcp.22838

Le Clainche, C., and Carlier, M. F. (2008). Regulation of actin assembly associated with protrusion and adhesion in cell migration. Physiol. Rev. 88, 489-513. doi: 10.1152/physrev.00021.2007

Lee, S. J., Park, M. H., Kim, H. J., and Koh, J. Y. (2010). Metallothionein-3 regulates lysosomal function in cultured astrocytes under both normal and oxidative conditions. Glia 58, 1186-1196. doi: 10.1002/glia.20998

Lee, S. J., Seo, B. R., Choi, E. J., and Koh, J. Y. (2014). The role of reciprocal activation of cAbl and Mstl in the oxidative death of cultured astrocytes. Glia 62, 639-648. doi: 10.1002/glia.22631

Linossi, E. M., Babon, J. J., Hilton, D. J., and Nicholson, S. E. (2013). Suppression of cytokine signaling: the SOCS perspective. Cytokine Growth Factor Rev. 24, 241-248. doi: 10.1016/j.cytogfr.2013.03.005

Liu, C., Li, Y., Yu, J., Feng, L., Hou, S., Liu, Y., et al. (2013). Targeting the shift from M1 to M2 macrophages in experimental autoimmune encephalomyelitis mice treated with fasudil. PLoS ONE 8:e54841. doi: 10.1371/journal.pone.0054841

Liu, X. A., Rizzo, V., and Puthanveettil, S. V. (2012). Pathologies of axonal transport in neurodegenerative diseases. Transl. Neurosci. 3, 355-372. doi: 10.2478/s13380-012-0044-7

Lobsiger, C. S., and Cleveland, D. W. (2007). Glial cells as intrinsic components of non-cell-autonomous neurodegenerative disease. Nat. Neurosci. 10, 1355-1360. doi: $10.1038 / \mathrm{nn} 1988$

Maragakis, N. J., and Rothstein, J. D. (2006). Mechanisms of Disease: astrocytes in neurodegenerative disease. Nat. Clin. Pract. Neurol. 2, 679-689. doi: 10.1038/ncpneuro0355

Mattila, P. K., and Lappalainen, P. (2008). Filopodia: molecular architecture and cellular functions. Nat. Rev. Mol. Cell. Biol. 9, 446-454. doi: 10.1038/nrm2406

McMillian, M. K., Thai, L., Hong, J. S., O'Callaghan, J. P., and Pennypacker, K. R. (1994). Brain injury in a dish: a model for reactive gliosis. Trends Neurosci. 17, 138-142.

Mleczak, A., Millar, S., Tooze, S. A., Olson, M. F., and Chan, E. Y. (2013). Regulation of autophagosome formation by Rho kinase. Cell. Signal. 25, 1-11. doi: 10.1016/j.cellsig.2012.09.010

Mueller, B. K., Mack, H., and Teusch, N. (2005). Rho kinase, a promising drug target for neurological disorders. Nat. Rev Drug. Discov. 4, 387-398. doi: $10.1038 / \mathrm{nrd} 1719$

Mueller, B. K., Mueller, R., and Schoemaker, H. (2009). Stimulating neuroregeneration as a therapeutic drug approach for traumatic brain injury. Br. J. Pharmacol. 157, 675-685. doi: 10.1111/j.1476-5381.2009.00220.x

Ng, E. L., and Tang, B. L. (2008). Rab GTPases and their roles in brain neurons and glia. Brain Res. Rev. 58, 236-246. doi: 10.1016/j.brainresrev.2008.04.006

Nisbet, D. R., Rodda, A. E., Horne, M. K., Forsythe, J. S., and Finkelstein, D. I. (2009). Neurite infiltration and cellular response to electrospun polycaprolactone scaffolds implanted into the brain. Biomaterials 30, 4573-4580. doi: 10.1016/j.biomaterials.2009.05.011

Nisbet, D. R., Rodda, A. E., Horne, M. K., Forsythe, J. S., and Finkelstein, D. I. (2010). Implantation of functionalized thermally gelling xyloglucan hydrogel within the brain: associated neurite infiltration and inflammatory response. Tissue Eng. Part A 16, 2833-2842. doi: 10.1089/ten.TEA.2009.0677

Okada, S., Nakamura, M., Katoh, H., Miyao, T., Shimazaki, T., Ishii, K., et al. (2006). Conditional ablation of Stat 3 or Socs 3 discloses a dual role for reactive astrocytes after spinal cord injury. Nat. Med. 12, 829-834. doi: 10.1038/nm1425

O’Shea, R. D., Lau, C. L., Farso, M. C., Diwakarla, S., Zagami, C. J., Svendsen, B. B., et al. (2006). Effects of lipopolysaccharide on glial phenotype and activity of glutamate transporters: evidence for delayed up-regulation and redistribution of GLT-1. Neurochem. Int. 48, 604-610. doi: 10.1016/j.neuint.2005.12.028

Panickar, K. S., and Norenberg, M. D. (2005). Astrocytes in cerebral ischemic injury: morphological and general considerations. Glia 50, 287-298. doi: 10.1002/glia.20181

Parpura, V., Heneka, M. T., Montana, V., Oliet, S. H., Schousboe, A., Haydon, P. G., et al. (2012). Glial cells in (patho)physiology. J. Neurochem. 121, 4-27. doi: 10.1111/j.1471-4159.2012.07664.x

Pirooznia, S. K., Dawson, V. L., and Dawson, T. M. (2014). Motor neuron death in ALS: programmed by astrocytes? Neuron 81, 961-963. doi: 10.1016/j.neuron.2014.02.024

Planas, A. M., Gorina, R., and Chamorro, A. (2006). Signalling pathways mediating inflammatory responses in brain ischaemia. Biochem. Soc. Trans. 34, 1267-1270. doi: 10.1042/BST0341267 
Puschmann, T. B., Zanden, C., De Pablo, Y., Kirchhoff, F., Pekna, M., Liu, J., et al. (2013). Bioactive 3D cell culture system minimizes cellular stress and maintains the in vivo-like morphological complexity of astroglial cells. Glia 61, 432-440. doi: 10.1002/glia.22446

Raad, M., El Tal, T., Gul, R., Mondello, S., Zhang, Z., Boustany, R. M., et al. (2012). Neuroproteomics approach and neurosystems biology analysis: ROCK inhibitors as promising therapeutic targets in neurodegeneration and neurotrauma. Electrophoresis 33, 3659-3668. doi: 10.1002/elps.201200470

Racchetti, G., D'Alessandro, R., and Meldolesi, J. (2012). Astrocyte stellation, a process dependent on Racl is sustained by the regulated exocytosis of enlargeosomes. Glia 60, 465-475. doi: 10.1002/glia.22280

Ridet, J. L., Malhotra, S. K., Privat, A., and Gage, F. H. (1997). Reactive astrocytes: cellular and molecular cues to biological function. Trends Neurosci. 20, 570-577.

Riento, K., and Ridley, A. J. (2003). Rocks: multifunctional kinases in cell behaviour. Nat. Rev. Mol. Cell. Biol. 4, 446-456. doi: 10.1038/nrm1128

Sagawa, H., Terasaki, H., Nakamura, M., Ichikawa, M., Yata, T., Tokita, Y., et al. (2007). A novel ROCK inhibitor, Y-39983, promotes regeneration of crushed axons of retinal ganglion cells into the optic nerve of adult cats. Exp. Neurol. 205, 230-240. doi: 10.1016/j.expneurol.2007.02.002

Schafer, D. P., Lehrman, E. K., and Stevens, B. (2013). The "quad-partite" synapse: microglia-synapse interactions in the developing and mature CNS. Glia 61, 24-36. doi: 10.1002/glia.22389

Schmid-Brunclik, N., Burgi-Taboada, C., Antoniou, X., Gassmann, M., and Ogunshola, O. O. (2008). Astrocyte responses to injury: VEGF simultaneously modulates cell death and proliferation. Am. J. Physiol. Regul. Integr. Comp. Physiol. 295, R864-R873. doi: 10.1152/ajpregu.00536.2007

Sheldon, A. L., and Robinson, M. B. (2007). The role of glutamate transporters in neurodegenerative diseases and potential opportunities for intervention. Neurochem. Int. 51, 333-355. doi: 10.1016/j.neuint.2007.03.012

Sofroniew, M. V. (2009). Molecular dissection of reactive astrogliosis and glial scar formation. Trends Neurosci. 32, 638-647. doi: 10.1016/j.tins.2009.08.002

Sofroniew, M. V. (2014). Multiple roles for astrocytes as effectors of cytokines and inflammatory mediators. Neuroscientist 20, 160-172. doi: 10.1177/1073858413504466

Sofroniew, M. V., and Vinters, H. V. (2010). Astrocytes: biology and pathology. Acta Neuropathol. 119, 7-35. doi: 10.1007/s00401-009-0619-8

Song, Y., Chen, X., Wang, L. Y., Gao, W., and Zhu, M. J. (2013). Rho kinase inhibitor fasudil protects against beta-amyloid-induced hippocampal neurodegeneration in rats. CNS Neurosci. Ther. 19, 603-610. doi: 10.1111/cns.12116

Takata, M., Tanaka, H., Kimura, M., Nagahara, Y., Tanaka, K., Kawasaki, K., et al. (2013). Fasudil, a rho kinase inhibitor, limits motor neuron loss in experimental models of amyotrophic lateral sclerosis. Br. J. Pharmacol. 170, 341-351. doi: 10.1111/bph.12277

Talantova, M., Sanz-Blasco, S., Zhang, X., Xia, P., Akhtar, M. W., Okamoto, S., et al. (2013). Abeta induces astrocytic glutamate release, extrasynaptic NMDA receptor activation, and synaptic loss. Proc. Natl. Acad. Sci. U.S.A. 110, E2518-E2527. doi: 10.1073/pnas.1306832110

Teo, W. E., He, W., and Ramakrishna, S. (2006). Electrospun scaffold tailored for tissue-specific extracellular matrix. Biotechnol. J. 1, 918-929. doi: 10.1002/biot.200600044

Titler, A. M., Posimo, J. M., and Leak, R. K. (2013). Astrocyte plasticity revealed by adaptations to severe proteotoxic stress. Cell Tissue Res. 352, 427-443. doi: 10.1007/s00441-013-1571-4

Tonges, L., Gunther, R., Suhr, M., Jansen, J., Balck, A., Saal, K. A., et al. (2014). Rho kinase inhibition modulates microglia activation and improves survival in a model of amyotrophic lateral sclerosis. Glia 62, 217-232. doi: 10.1002/glia.22601

Trendelenburg, G., and Dirnagl, U. (2005). Neuroprotective role of astrocytes in cerebral ischemia: focus on ischemic preconditioning. Glia 50, 307-320. doi: 10.1002/glia.20204

Turner, B. J., and Talbot, K. (2008). Transgenics, toxicity and therapeutics in rodent models of mutant SOD1-mediated familial ALS. Prog. Neurobiol. 85, 94-134. doi: 10.1016/j.pneurobio.2008.01.001
Vargas, M. R., and Johnson, J. A. (2010). Astrogliosis in amyotrophic lateral sclerosis: role and therapeutic potential of astrocytes. Neurotherapeutics 7, 471-481. doi: 10.1016/j.nurt.2010.05.012

Volterra, A., and Meldolesi, J. (2005). Astrocytes, from brain glue to communication elements: the revolution continues. Nat. Rev. Neurosci. 6, 626-640. doi: $10.1038 / \mathrm{nrn} 1722$

Wang, X., Su, B., Lee, H. G., Li, X., Perry, G., Smith, M. A., et al. (2009). Impaired balance of mitochondrial fission and fusion in Alzheimer's disease. J. Neurosci. 29, 9090-9103. doi: 10.1523/JNEUROSCI.1357-09.2009

Wanner, I. B., Anderson, M. A., Song, B., Levine, J., Fernandez, A., GrayThompson, Z., et al. (2013). Glial scar borders are formed by newly proliferated, elongated astrocytes that interact to corral inflammatory and fibrotic cells via STAT3-dependent mechanisms after spinal cord injury. J. Neurosci. 33, 12870-12886. doi: 10.1523/JNEUROSCI.2121-13.2013

Watzlawick, R., Sena, E. S., Dirnagl, U., Brommer, B., Kopp, M. A., Macleod, M. R., et al. (2014). Effect and reporting bias of RhoA/ROCK-blockade intervention on locomotor recovery after spinal cord injury: a systematic review and metaanalysis. JAMA Neurol. 71, 91-99. doi: 10.1001/jamaneurol.2013.4684

Wong, D. Y., Hollister, S. J., Krebsbach, P. H., and Nosrat, C. (2007). Poly(epsiloncaprolactone) and poly (L-lactic-co-glycolic acid) degradable polymer sponges attenuate astrocyte response and lesion growth in acute traumatic brain injury. Tissue Eng. Part A 13, 2515-2523. doi: 10.1089/ten.2006.0440

Yang, J., Carra, S., Zhu, W. G., and Kampinga, H. H. (2013). The regulation of the autophagic network and its implications for human disease. Int. J. Biol. Sci. 9, 1121-1133. doi: 10.7150/ijbs.6666

Yu, J. Z., Ding, J., Ma, C. G., Sun, C. H., Sun, Y. F., Lu, C. Z., et al. (2010). Therapeutic potential of experimental autoimmune encephalomyelitis by Fasudil, a Rho kinase inhibitor. J. Neurosci. Res. 88, 1664-1672. doi: 10.1002/jnr.22339

Zagami, C. J., Beart, P. M., Wallis, N., Nagley, P., and O'Shea, R. D. (2009). Oxidative and excitotoxic insults exert differential effects on spinal motoneurons and astrocytic glutamate transporters: Implications for the role of astrogliosis in amyotrophic lateral sclerosis. Glia 57, 119-135. doi: 10.1002/glia. 20739

Zagami, C. J., O’Shea, R. D., Lau, C. L., Cheema, S. S., and Beart, P. M. (2005). Regulation of glutamate transporters in astrocytes: evidence for a relationship between transporter expression and astrocytic phenotype. Neurotox. Res. 7, 143-149. doi: 10.1007/BF03033783

Zuidema, J. M., Hyzinski-Garcia, M. C., Van Vlasselaer, K., Zaccor, N. W., Plopper, G. E., Mongin, A. A., et al. (2014). Enhanced GLT-1 mediated glutamate uptake and migration of primary astrocytes directed by fibronectincoated electrospun poly-L-lactic acid fibers. Biomaterials 35, 1439-1449. doi: 10.1016/j.biomaterials.2013.10.079

Conflict of Interest Statement: The authors declare that the research was conducted in the absence of any commercial or financial relationships that could be construed as a potential conflict of interest.

Received: 26 September 2014; accepted: 04 February 2015; published online: 20 February 2015.

Citation: O'Shea RD, Lau CL, Zulaziz N, Maclean FL, Nisbet DR, Horne MK and Beart PM (2015) Transcriptomic analysis and 3D bioengineering of astrocytes indicate ROCK inhibition produces cytotrophic astrogliosis. Front. Neurosci. 9:50. doi: 10.3389/ fnins.2015.00050

This article was submitted to Neuropharmacology, a section of the journal Frontiers in Neuroscience.

Copyright (c) 2015 O'Shea, Lau, Zulaziz, Maclean, Nisbet, Horne and Beart. This is an open-access article distributed under the terms of the Creative Commons Attribution License (CC BY). The use, distribution or reproduction in other forums is permitted, provided the original author(s) or licensor are credited and that the original publication in this journal is cited, in accordance with accepted academic practice. No use, distribution or reproduction is permitted which does not comply with these terms. 